\title{
La Gestación Subrogada: Aspectos Éticos y Jurídicos en el Derecho español
}

\section{Subrogated Gestation: Ethical and Legal Aspects in Spanish Law}

\author{
DOI: https://doi.org/10.17981/juridcuc.17.1.2021.12
}

Fecha de Recepción: 2020/12/13 Fecha de Aceptación: 2021/01/21

Clara Sarasol Barres $\odot$

Universitat Politècnica de València. Valencia (España)

clasaba1@etsiamn.upv.es

\author{
Francisca Ramón Fernández 10 \\ Universitat Politècnica de València. Valencia (España) \\ frarafer@urb.upv.es
}

Para citar este artículo:

Sarasol, C. y Ramón, F. (2021). La Gestación Subrogada: Aspectos Éticos y Jurídicos en el Derecho español. Jurídicas CUC, 17(1), 323-366. DOI: http://dx.doi.org/10.17981/juridcuc.17.1.2021.12

\section{Resumen}

En el presente trabajo se analizarán los principales problemas jurídicos y éticos que presenta la gestación subrogada en el Derecho Español. El objetivo principal es poder valorar de manera razonada cuál sería la mejor solución para la gestación subrogada, si regularla o prohibirla, seguida de un estudio ético sobre las consecuencias de esta práctica sobre los derechos de la mujer subrogada y el bebé nacido. La metodología empleada partirá de su concepto y terminología, así como el análisis de la principal legislación aplicable española, para obtener unas conclusiones válidas. El ordenamiento jurídico español, a pesar de no permitir la gestación subrogada, da lugar a cierta incertidumbre legislativa, al dejar lagunas a través de las cuales se salva la prohibición. Sin embargo, sólo aquellos con un alto poder adquisitivo podrán acceder y lo harán a expensas de otras personas con peores condiciones de vida.

Palabras clave: Bioética; fecundación in vitro; gestación subrogada; legislación; derecho español

\section{Abstract}

In this paper the main legal and ethical problems presented by surrogacy in Spanish Law will be analyzed. The main objective is to be able to reasonably assess what would be the best solution for surrogacy, whether to regulate or prohibit it, followed by an ethical study on the consequences of this practice on the rights of the surrogate woman and the baby born. The methodology used will start from its concept and terminology, as well as the analysis of the main applicable Spanish legislation, to obtain valid conclusions. The Spanish legal system, despite not allowing surrogacy, gives rise to some legislative uncertainty, by leaving loopholes through which the prohibition is overcome. However, only those with high purchasing power will be able to access and will do so at the expense of other people with worse living conditions.

Keywords: Bioethics, in vitro fertilization, legislation; surrogacy; spanish law 


\section{INTRODUCCIÓN}

A lo largo del tiempo se han ido desarrollando las técnicas de reproducción asistida con la finalidad de solucionar los problemas de infertilidad y ofreciendo la posibilidad de tener descendencia a mujeres sin pareja o a mujeres homosexuales. Desde luego este avance científico por sí mismo no ofrece solución al deseo por parte de hombres solteros o hombres homosexuales, ni tampoco a las mujeres que no quieren pasar por el proceso de gestación y parto para tener descendencia.

Ello ha llevado a buscar opciones más allá con la finalidad de poder reproducirse, que, sumado a las dificultades intrínsecas del proceso de adopción, y el deseo que el niño o la niña lleve los genes del padre o la madre, ha llevado a establecer como alternativa la gestación subrogada (Herrán, 2019).

A lo largo del desarrollo y socialización de esta práctica, la gestación subrogada ha ido generando un debate ético y legal en el seno de la sociedad. No obstante, todo ello es relativamente reciente, ya que, en el año 2014, con la noticia de Baby Grammy, es cuando muchas personas se dieron cuenta de la existencia de la gestación subrogada. El debate se generó en el ámbito social de forma inmediata, ya que en este caso en concreto, ya que los "padres de intención", habían intentado hacer abortar a la mujer que había concebido para darles un hijo (Benítez, 2019), la mujer subrogada, y el posterior abandono de los padres que habían contratado la gestación, por el hecho de que Gammy tenía síndrome de Down, y el debate también se centraba en el poder que tenían estas personas contratando sobre la vida de la mujer gestante y de los bebés.

La pregunta base del conflicto era si a pesar de ser científicamente posible, ello era éticamente aceptable. Una pregunta que se plantean los legisladores desde el primer caso documentado en 1976 en Estados Unidos, con tal de intentar dar una respuesta adecuada a la situación generada. 


\section{Matenidad y Paternidad: Algunas consideraciones}

\section{¿Qué razones hay para tener hijos?}

La familia como institución social no es eterna, sino que consiste en un fenómeno histórico sujeto a las transformaciones en el modelo de producción y reproducción (Itaia, 2019). Por tanto, la familia como tal la conocemos en nuestra sociedad actual comienza a desarrollarse a partir del surgimiento de la propiedad privada.

Si bien es cierto que la producción de los medios de subsistencia y la reproducción de la especie ha representado siempre un factor decisivo en la historia, es el momento en el que el régimen familiar se ve sometido a las relaciones de propiedad que aparece una necesidad de reproducción humana que va más allá (Engels, 1884).

Con la aparición de la propiedad privada de los medios de producción (sobre todo a raíz de la Revolución Industrial y el auge de las fábricas) comienza la preocupación sobre quién heredará aquellas propiedades. De esta forma comienza a generarse una estructura social cada vez más definida con el padre, la madre, y los hijos, donde ha de quedar muy clara la filiación para poder determinar correctamente quién será el heredero. Vemos cómo con la evolución de las relaciones de producción, evoluciona también esta institución hasta la familia burguesa. Por un lado, ésta surge para poder asegurar la consolidación o aumento de la propiedad privada que se posee, de manera que perdure la base de su poder como clase social. Por otro lado, esta familia se ha de asegurar que tiene descendencia para poner mantener las posesiones dentro de su familia.

En cambio, en la clase trabajadora vemos una dinámica diferente, ésta no tiene necesidad de tener descendencia a quien transmitirle los medios de producción por la falta de poseerlos, ya que en realidad no dispone de ellos. No obstante, la burguesía requerirá la reproducción de la fuerza del trabajo como uno de los pilares que garanticen la acumulación de riqueza que la consolide como clase (Itaia, 2019), y de esta manera, las familias obreras se convierten en la herramienta de reproducción biológica de la fuerza de trabajo. 
Además, esta renovación garantiza la retirada de parte de la clase trabajadora del mercado laboral, ya que hay una nueva generación que la sustituirá; por otro lado, los hijos suponen nuevos ingresos necesarios para la casa.

Desde luego, la sociedad ha ido evolucionando y, estas son las razones de fondo, se ha ido generando otras razones por las cuales la gente decide tener hijos. Pero hoy por hoy, esta decisión se ve influida por condiciones subjetivas, biológicas, económicas y sociales (Biffi y Marques, 2017, p. 207).

Existe el deseo de formar una familia, que puede estar basado en la naturaleza del ser humano, ya que la reproducción se considera una finalidad vital, o puede responder al deseo de transmitir los genes. Otras personas deciden tener hijos para vivir una experiencia única en la vida, o bien para poder darle amor o compartir nuevas emociones con ella.

También puede aparecer el deseo de tener hijos por razones relacionadas con el pasado, por nostalgia de épocas pasadas, cuando se era un niño, o bien para demostrar que se puede ser mejor padre/ madre que los propios.

Del mismo modo, hay otras razones que no se pueden dejar de mostrar, tan buenas como las anteriores, como podría ser el deseo de tener hijos para poder estar acompañados en la vejez o para cumplir con las expectativas de la sociedad. Finalmente, puede surgir el deseo de tener un hijo como una necesidad para superar una crisis, ya sea un problema de pareja, una crisis existencial, o la muerte de algún hijo o familiar, entre otros ejemplos (Romeo, 2019; Muñoz, 2019).

Así pues, podríamos decir que la decisión de tener hijos actualmente se ve profundamente influida por una serie de prerrequisitos. Estos dependerían de características personales referentes al deseo de tener hijos y formar una familia; de las relaciones interpersonales respecto a la relación con la pareja, y la influencia de ésta, así como el contexto social, e incluso para lograr una curación, como es el caso de la concepción de los llamados "bebés medicamentos" (Moya y Ramón, 2018, p. 81; Ramón, 2019, p. 69; 
Ridao y Ramón, 2020, p. 39). También tienen gran peso los factores socioeconómicos, ya que en el mundo occidental tener una hija es más un gasto que una inversión que permita obtener más ingresos, razón por la cual es importante la estabilidad personal con una seguridad financiera. En último término, aparecen factores temporales en relación con las cuestiones biológicas y madurez persona, a pesar de que no son considerados como aspectos muy relevantes (Biffi y Marques, 2017; Cañal, Cocina, Ardines, Carro y Torre, 2019).

\section{La Gestación Subrogada}

\section{Orígenes}

Aunque la gestación subrogada parece una práctica actual, ya hay menciones de ella en el Génesis 16 (Antiguo Testamento), donde se explica que Sara, la esposa de Abraham, no pudo tener hijas, sino que con la esclava Agar tuvieron un hijo al que llamaron Ismael (Biblia versión Reina Valera, 2009). Ella aparece de nuevo en Génesis 30 (Antiguo Testamento), donde Raquel no puede dar hijos a Jacob y le ofrece a su criada Bilha argumentando que "dará a luz de rodillas, y yo también tendré hijos de ella”; y también Lea, la otra esposa de Jacob, tiene hijos a través de su criada Zilpa (Biblia versión Reina Valera, 2009). También está presente en el Código Hammurabi (1750 a. C.), donde se decreta en las leyes 144 a 147 que las mujeres que no pueden tener hijos deben ofrecer una esclava al marido para tenerlas (Lara, 1982).

Parece que en muchas sociedades era una práctica extendida, como por ejemplo, el Antiguo Egipto, donde muchos faraones tenían hijas a través de sus siervos (Svitnev, 2011); o la antigua Roma, donde había una práctica social conocida como "asignación del vientre" a través de la cual los romanos cedieron a sus esposas en el momento del embarazo, pero también cuando una mujer era estéril, podía tener descendencia a través de una concubina (García, 2014). 


\section{Concepto}

A medida que han progresado tanto las técnicas de reproducción asistida como la concepción social de la familia (Ramón, 2018), la definición de gestación sustituta ha evolucionado (Ramón, 2017; Avilés y Ramón, 2019) ${ }^{1}$.

En este sentido, en la definición hecha por Coleman en 1982 se puede ver que sólo era posible la gestación subrogada con la gestante proporcionando sus gametos y con inseminación artificial. Además, los comitentes tenían que ser una pareja heterosexual casada infértil con la aportación genética del hombre (Lamm, 2013; Sánchez, 2019a; Magariños, 2019; Palacios, 2019).

Más actual es la explicación de la Conferencia de La Haya sobre Derecho Internacional Privado (COHADIP), que establece a la madre sustituta como "la mujer que acepta renunciar a un niño (o hijos) para el comité del padre y renuncia a sus derechos parentales después del nacimiento" (COHADIP, 1993). Mientras tanto, en la Unión Europea, el Departamento de Derechos de los Ciudadanos y Asuntos Constitucionales describe la gestación subrogada como "una práctica a la que una mujer queda embarazada con la intención de entregar el niño a otra persona al nacer" (Conferénce de La Haye de Droit Internacional Privé, 2012, p. 10).

En términos jurídicos, se asumirá la definición de la Jurisprudencia, en concreto de la Sentencia de la Audiencia Provincial de Valencia (SAP V 5738/2011, 2011):

[...] un contrato, oneroso o gratuito, a través del cual una mujer consiente llevar a cabo la gestación, a través de técnicas de reproducción asistida, aportando también su óvulo, con el compromiso de entregar al recién nacido a los comitentes, que pueden ser una persona o una pareja, casados entre sí o no, que a su vez pueden aportar sus gametos (p. 2).

1 Cuando se refiere al trabajo a una mujer/madre gestante/subrogada, entendemos a aquellas personas con un sistema reproductivo femenino, entendiendo que el sexo biológico y el género no siempre deben estar vinculados. Sin embargo, esto se ha hecho con el fin de facilitar la comprensión de ser la forma socializada. 


\section{Terminología}

La legislación española utiliza el término "gestación por sustitución", tanto en el Informe (1986) de la Comisión Especial para el Estudio de la Fertilización " In vitro » y la Inseminación Artificial Humana del Congreso de los Diputados, como en la Ley 14/2006, sobre Técnicas de reproducción humana asistida.

Sin embargo, como señala Lamm (2013), la terminología para referirse a esta técnica es muy extensa y diversa: maternidad sustituta, alquiler de úteros, madres sustitutas, alquiler de úteros, donación temporal de útero, embarazo en nombre de otro, embarazo suplente, maternidad sustituta, licencia de maternidad, licencia de maternidad, maternidad, entre otros.

Tampoco en el derecho comparado se encuentra un término único, ya que los anglosajones utilizan madre sustituta y suplente. En Francia, mère de substitution, mère porteuse, gestation-pourautrui, mère de replacement i prêt d'uterus. De otra parte, en Italia tenemos affito di utero o locazione di utero, mientras que en Alemania, Leihmutter (Lamm, 2013; Gutiérrez, 2019; Reyes, 2019).

Como puede verse, el desacuerdo ya aparece con el mismo término para referirse a ella y se compromete a utilizar uno u otro considerando que la terminología no es neutral e implica una evaluación ética.

Entre los diferentes términos, maternidad y gestación se considera más correcta esta última, ya que la primera engloba una realidad mucho más extensa, tanto biológica como social, que va más allá de la gestación y dar a luz a un bebé, que sí corresponde al proceso de gestación. En cuanto a la gestación o subrogada $o$ sustitución, la Real Academia Española (RAE, 2020) define el subrogado como "sustituir o poner a alguien o algo en lugar de otra persona o cosa" y el Instituto de Estudios Catalanes (IEC, 2020) lo define como "asumir un derecho, una obligación, una función, de otros"; así, se considera correcta el uso de la gestación subrogada, ya que se refiere a una mujer que gesta en el lugar 
de otra. Sin embargo, tanto la sustitución como el subrogado serían sinónimos, pero en nuestra opinión, el término subrogar muestra mejor la crudeza de esta práctica, por lo que he optado por utilizarla.

Aun así, consideramos que este término, a pesar de representar un poco las implicaciones subyacentes de esta técnica, representa un eufemismo para el que realmente debe llamarse vientre (o útero) para alquilar. Se cree que este último término hace una mejor referencia a la relación contractual existente en este procedimiento (López, 2019). Sin embargo, este trabajo utiliza la "gestación subrogada" para ser un término más similar al utilizado en la legislación que se analizará en este documento.

\section{Primeros intentos de reproducción asistida}

Con las técnicas de reproducción asistida aparecen nuevas posibilidades para la gestación sustituta. El primer nacimiento por inseminación artificial tuvo lugar en 1785, de la mano del cirujano escocés John Hunter (Barcelona FIV, 2012). Con esto, el primer acuerdo de subrogación con inseminación artificial documentada data de 1976 en los Estados Unidos de América (USA), patrocinado por el abogado Noel Keane, quien más tarde fundó Suplente Family Service Inc. (López y Aparisi, 2012). Dos años más tarde, el 25 de julio de 1978, el primer bebé nació como resultado de la fecundación in vitro gracias al fisiólogo Robert Edwards, el ginecólogo Patrick Steptoe y el embriólogo Jean Purdy (Sánchez, 2020). Unos años más tarde, en 1984, tuvo lugar el primer caso de gestación subrogada al que la mujer gestacional no proporcionó su material genético, sino que había transferido los óvulos de una mujer sin útero (Lamm, 2013).

En España, la primera inscripción de los niños nacidos con esta técnica figura en la Resolución del 18 de febrero de 2009 de la Dirección General de Registros y Notariado (Díaz, 2019; Álvarez, 2019; Andreu, 2019). 


\section{Tipos}

La gestación sustituta puede clasificarse según varios elementos, entre ellos: quién es la parte comitiva, la participación de la madre sustituta y la técnica de reproducción asistida utilizada (Boada y Coroleu, 2010). Por la parte comitente podemos encontrar: pareja heterosexual (casada o no); pareja homosexual femenina o mujer sola; pareja homosexual masculina o hombre solo; respecto a la participación de la mujer subrogada, puede realizar la gestación o realiza la gestación y aporta óvulos. En cuanto a las técnicas de reproducción asistida, se puede utilizar la inseminación artificial o la fecundación in vitro.

Otro elemento importante es el origen de los gametos que pueden pertenecer a la mujer gestante, la pareja o los donantes (Boada y Coroleu, 2010; Aviléz y Ramón, 2019; Rosell y Ramón, 2020), que pueden ser óvulos de la mujer subrogada, óvulos de la mujer comitente, óvulos de donante, semen del hombre comitente o semen de donante.

\section{LEGislación APLiCABLE A LA GESTACiÓN SUBROGADA}

La inicial regulación de la reproducción asistida en el Derecho Español: la Ley 35/1988, de 22 de noviembre, de Técnicas de reproducción asistida

Las técnicas de reproducción asistida llevaron a una revolución en el campo de la reproducción que requería regulación. Por esta razón, surgió la Ley 35/1988, del 22 de noviembre de 1988, sobre Técnicas de reproducción asistida (Ferrer, 2019; Vidal, 2019). Por un lado, nació para aliviar la incertidumbre social generada como resultado de la posible manipulación de embriones para la investigación; pero también para poder regular las posibles aplicaciones de estas técnicas, específicamente la gestación en una sola mujer y la gestación subrogada ("gestación de sustitución” en la Ley) (Lledó, 2019a; Lledó y Gutiérrez, 2018; Lledó y Monje, 2020). 
Respecto a dicha motivación, ya lo precisó la Ley 35/1988, en su Exposición de Motivos que señalo los siguientes aspectos que pasamos a señalar:

- La aparición de avances y descubrimientos científicos y tecnológicos.

- El desarrollo de las diversas técnicas como la inseminación artificial, tanto del marido o varón como de donante; la fecundación in vitro con transferencia de embrión y la transferencia intratubárica de gametos.

- La posibilidad de tratar la esterilidad humana a través de algunas de las técnicas indicadas en el caso que otros métodos no resulten eficaces, y también su utilización en otros casos médicos en los que no resulte posible la concepción de forma natural.

- La utilización de métodos de diagnóstico a través de los óvulos ya fecundados con finalidad terapéutica, de investigación o experimentación y su repercusión en el ámbito social, ético, biomédico y jurídico.

- La necesidad de establecer una estrecha colaboración entre la sociedad y la ciencia que lleve como prioridad el respeto a los derechos y libertades fundamentales del ser humano, siempre actuando en su beneficio, pero estableciendo unos límites adecuados. Por ello, se deben crear Comisiones de carácter multidisciplinar para recoger el criterio de la población y la opinión de los expertos en reproducción asistida, estableciendo los límites de aplicación y las posibilidades de las técnicas mencionadas.

- La necesaria argumentación de las técnicas reproductivas sobre su aceptación o rechazo sin estar mediatizadas por presiones ideológicas, religiosas o partidistas, teniendo en cuenta la ética civil, y procurando el interés general de acuerdo con los preceptos constitucionales. 
La actual regulación de la reproducción asistida en el Derecho Español: la Ley 14/2006, de 26 de mayo, sobre técnicas de reproducción humana asistida

Actualmente, la Ley 14/2006 sobre Técnicas de reproducción humana asistida, es la única que se refiere al Estado español en la gestación subrogada. Esto, en el artículo 10, titulado "Gestación por sustitución", en el que se establece la nulidad de pleno derecho del contrato de gestación, ya sea de forma gratuita o mediante precio, que realice una mujer que después renuncia a la filiación materna en favor de la persona que contrata la gestación o en favor de una tercera persona (Ley 14/2006, art. 10).

Se establece que la filiación de los hijos que nazcan mediante gestación de sustitución se determinará por el parto. Y se podrán establecer las correspondientes acciones de reclamación de la paternidad respecto al padre biológico, tal y como establece el Código Civil (1889).

Esta ley dispone la nulidad del contrato de conformidad con el Código Civil (1889, art. 1271), el cual ordena que "pueden ser objeto de contrato todas las cosas que no estén fura del comercio de los hombres", interpretando que la gestación debe quedar fuera del comercio y que el embrión no es res extra commercium (Marabel, 2019).

Sin embargo, viendo la forma en que se redacta la ley, se demuestra que la gestación subrogada no está expresamente prohibido por la legislación española, sino que se limita a declarar nulo el contrato que se lleva a cabo (Gálvez, 2019; Fernández, 2020). Sin embargo, en caso de contrato oneroso, las medidas punitivas se encuentran en el Código Penal (1995, art. 221).

Con esto, aún así, no sería punible cuando el contrato fuera altruista y, además, la nulidad de este contrato y la posible pena se determinan una vez que se ha cumplido y no se puede devolver, habiendo nacido ya un menor el cual debe ser protegido.

Para proteger a este recién nacido, el artículo 10 de la Ley 14/2006 lo contempla en los dos puntos del mismo (Cardona, 2019). De esta forma, en cumplimiento de la Ley 20/2011 (art. 44), del Registro Civil, el menor quedará registrado determinando la filiación de la progenitora. 
También el artículo 10.3 (Ley 14/2006) tiene como objetivo asegurar la tutela parental de la niña, ya que permite la reclamación de paternidad por parte del padre siempre que él había proporcionado el semen. En este caso, se convierte en una excepción a la nulidad del contrato, ya que confirma la filiación del padre incluso si el hijo es el resultado de un contrato de gestación subrogada.

Con estos hechos, aparecen nuevos conflictos. Por un lado, con la determinación de la filiación por el parto, la madre sustituta podía quedarse con la hija, incumpliendo el contrato y sin tener que indemnizar a los comitentes. Por otro lado, con el reconocimiento de la filiación del padre biológico, esta práctica se está legalizando de facto.

Siguiendo esta última línea, y aprovechando la ambigüedad de la Ley 14/2006, la Ley 20/2011 (art. 44.4), del Registro Civil, establece que el acceso a la filiación materna se restringirá en los casos en que la madre por motivos así lo solicite y siempre que renuncie a ejercer los derechos derivados de esta filiación. Se entiende que este artículo se refiere a permitir la adopción de bebés, sin embargo, podrían tener la intención de incluir la gestación subrogada en este caso.

Añadiendo, el artículo 45 de esta misma ley, que se refiere a quién debe promover el registro de nacimiento, plantea la posibilidad de la renuncia a la hija en el momento del nacimiento (Ley 20/2011).

Este punto crea conflicto, ya que se puede esperar que sea posible renunciar a una hija. Más allá, también podría entenderse que se refiere a la adopción, pero entra en contradicción con el Código Civil (1889, art. 177.2).

Además de ello, aunque la gestación subrogada se utilizaría como tipo de adopción, no podría en ningún caso acordar el parto del recién nacido antes del nacimiento, como se hace en los contratos de gestación subrogada, ya que el Código Civil establece un margen mínimo de un mes y medio (Casado e Ibáñez, 2014). Además, la renuncia a la filiación en casos de embarazo suplente se realiza mucho antes del nacimiento, antes de la gestación; sin embargo, podría representar una forma de proteger y permitir la gestación subrogada en España (Marrades, 2017a). 
LA INSCRIPCIÓN EN EL REGISTRO DE LA FILIACIÓN DE LOS NaCidos mediante Gestación subRogada

Instrucción de 5 de octubre de 2010, de la Dirección General de los Registros y del Notariado sobre régimen registral de la filiación de los nacidos mediante gestación por sustitución

El 18 de febrero de 2009, la Dirección General de los Registros y del Notariado (DGRN, 2009) emitió una Resolución que permitía la inscripción en el Registro Civil de dos niños nacidos como resultado de un contrato de embarazo suplente en California. Esta Resolución estableció una serie de condiciones que se establecerían en la Instrucción de 5 de octubre de 2010, de la Dirección General de Registros y Notarios (DGSJFP, 2010), sobre un régimen de registro de la filiación de los nacidos a través de la gestación sustituta.

Esta Instrucción permite el registro de las personas nacidas por contratos de embarazo suplente fuera de España como hijas de los comitentes. Además, como se expresa en este documento, nace con la intención de garantizar "la plena protección jurídica del interés superior del menor", así como "la protección de las mujeres que se prestan a esta técnica de reproducción, renunciando a sus derechos como madres" (DGSJFP, 2010, párr. 5).

Para ello, establece como condiciones que la madre sustituta ha consentido libremente, con plena capacidad y conocimiento de la causa y respetando sus derechos procesales, así como la firmeza de la decisión y la irrevocabilidad de los consentimientos (Salazar, 2017; Lluch y Ramón, 2017; Belinchón, 2019). Además, existe un requisito fundamental que exige una decisión prejudicial del país en el que se ha celebrado el contrato, tramitado en un procedimiento similar al español de jurisdicción voluntaria; y en caso de ser de carácter contencioso, se requerirá un procedimiento exequatur (Abellán-García, 2016).

Teóricamente, trata de proporcionar un marco de protección que permita el acceso al Registro Civil español de los nacidos en el extranjero a través de esta práctica, que garantice que la voluntad de la persona gestante sea gratuita, que garantice que no se trate de 
trata de niñas y que no inhabilite el derecho del niño a conocer su origen biológico (Lamm, 2016). Sin embargo, se está produciendo un fraude de derecho por vía administrativa, ya que está legalizando de facto esta práctica, contra la Ley 14/2006, al permitir que la filiación reconozca los efectos jurídicos a los contratos y también la renuncia a la filiación de la mujer subrogada.

\section{Postura de la jurisprudencia respecto a la inscripción en el registro de la filiación de los nacidos mediante gestación subrogada}

En cuanto a las consecuencias en la jurisprudencia de esta Instrucción, cabe destacar la Sentencia del Tribunal Provincial de Valencia 826/2011, de 23 de noviembre, que admitió la sentencia que dejó "sin elegido el registro de nacimiento" dictada por la DGRN el 18 de febrero de 2009 en el Registro Consular Civil de Los Ángeles. Es decir, dictó en contra de la Instrucción comentada. En este mismo sentido, en la sentencia 247/2014 del Tribunal Supremo, de 6 de febrero, que posteriormente se discute, se reafirmó en la sentencia anterior (Marabel, 2019).

Sin embargo, la sentencia del Tribunal Europeo de Derechos Humanos, Cas Menesson y Labasse contra Francia, de 26 de junio de 2014, ratificó de alguna manera la DGRN sobre la base de la protección del interés del menor. A continuación, esta última emitió una Circular el 11 de julio de 2014 con el fin de mantener la validez de la Instrucción de 5 de octubre de 2010 (Marabel, 2019; Sánchez, 2019b).

Además, se emitió otra Instrucción resultante del reconocimiento de la paternidad, realizada de conformidad con los requisitos exigidos por la ley aplicable para su plena validez y eficacia; sin una sentencia previa de un proceso judicial de reclamación de filiación, pero con pruebas adicionales, para la ley aplicable son suficientes para "inequívocamente acreditar esta filiación paterna" (DGRN, 2019a, p. 14). Sin embargo, en poco más de veinticuatro horas, el Ministerio de Justicia de España emitió una declaración que dejó en vigor esta Instrucción, reiterada por medio de la Instrucción de 
la DGRN de 18 de febrero de 2019 (DGRN, 2019b), sobre actualización del régimen registral de la filiación de los nacidos mediante gestación por sustitución (Marabel, 2019).

Por lo tanto, la validez de la Instrucción de 5 de octubre de 2010 permanece (Monje, 2019; Vilar, 2019).

\section{Aspectos Jurídicos y Éticos}

\section{Aspectos jurídicos}

\section{- El Derecho a tener descendencia}

El deseo de tener hijos es una realidad, un producto de la sociedad y el desarrollo de la historia. Parece en el sentido que se ha explicado al principio de este trabajo y ha evolucionado a medida que la sociedad lo ha hecho, manteniendo sus cimientos. Sin embargo, ¿existe el derecho a tener descendencia?

El derecho a tener descendencia, el derecho a procrear o el derecho a la reproducción humana no existen explícitamente en el ordenamiento jurídico del Estado español, pero tampoco en la normativa internacional, aunque ciertamente podría entenderse como un derecho derivado de otros.

El derecho principal bajo el cual podría sostenerse sería el derecho a fundar una familia contenida en varios textos internacionales: el artículo 16 de la Declaración Universal de Derechos Humanos de 1948, el artículo 12 del Convenio Europeo de Derechos Humanos de 1950 y el artículo 23.2 del Pacto Internacional de Derechos Civiles y Políticos de 1966 (Castellanos, 2019).

Parte de la doctrina española también ha defendido el derecho a procrear como derecho derivado de otros derechos consagrados en la Constitución Española (CE): la libertad como valor superior del ordenamiento jurídico (art. 1.1), el derecho a la dignidad humana y el libre desarrollo de la personalidad (art. 10.1), la vida y la integridad física y moral (art. 15), la libertad (art. 17), la intimidad personal y familiar (art. 18.1) y el derecho a la protección de la familia (art. 39.1) (Redondo, 2016). 
Por otro lado, un sector también lo encuentra el fundamento en el artículo 6.1 de la Ley 14/2006, que establece que cualquier mujer mayor de 18 años puede utilizar las técnicas de reproducción asistida reguladas por la ley, de modo que se entiende aquí un derecho de acceso a técnicas de reproducción asistida que se extienden al derecho a la reproducción (Redondo, 2016; Enguer y Ramón, 2018).

Anteriormente, en 1994 durante la Conferencia Mundial sobre la Población y el Desarrollo, y en 1995 para la 4 a Conferencia Mundial de la Mujer, se admitió la existencia de los derechos reproductivos, que consistía en el derecho a decidir el número de hijos y el espacio entre nacimientos, teniendo en cuenta las obligaciones con los hijos ya nacidos y futuros (Marrades, 2017a). Este caso es lo más parecido a reconocer el derecho a tener descendencia, pero lo que realmente defiende es la libertad de decisión cuando se trata de procrear, y no el derecho a procrear.

Frente a los derechos reconocidos en las CE que podrían proteger el derecho a reproducirse, se puede concluir definitivamente la inexistencia de este derecho. Sin embargo, trabajando en la posibilidad de que pudiera ser acomodado por lo que se discutió anteriormente, debe tenerse en cuenta que no sería un derecho absoluto, ya que no lo es. Este derecho no implicaría que su ejercicio costaría lo que cuesta, sino que tendría límites. Por un lado, estaría limitada por la ley, ya que no podría tener descendientes de tal manera que se incumplieran las leyes, como podría ser la Ley 14/2006 (art. 10). Y, por otro lado, estaría obligado por otros derechos, en el caso de la gestación subrogada, por la dignidad de las mujeres y los menores y otros derechos que se violan con esta práctica.

De hecho, como dice González, deseo "que puede ser totalmente comprensible, si cruzan la línea que los separa de la dignidad de las personas, dejan de tener espacio en el mundo del derecho" (Castellanos, 2019, p. 74). 


\section{- El Derecho a la dignidad de la persona}

La Constitución Española (CE, 1978) establece que "la dignidad de la persona, los derechos inviolables inherentes a él, el libre desarrollo de la personalidad, el respeto a la ley y los derechos de los demás son la base del orden político y de la paz social" (art. 10.1). En consecuencia, en el caso de que la gestación subrogada viole la dignidad de la persona, ya sea la mujer subrogada o el menor nacido, esta práctica debe evitarse (Lázaro, 2019). A continuación, se analiza si la gestación subrogada es un ataque a la dignidad o no.

La dignidad es el fundamento último de los derechos y basado en el imperativo categórico de Kant que indica racionalmente cuál debe ser nuestro patrón de conducta, prohíbe instrumentalizar a los seres humanos: "Obra de manera que utilizas la humanidad, tanto a tu persona como a cualquier otra persona, siempre como fin al mismo tiempo y nunca como un medio" (Marrades, 2017a).

En la gestación subrogada, sin embargo, la mujer subrogada se utiliza como un medio, ya que se gesta para otra persona basada en una relación contractual, es un instrumento para lograr lo que los comitentes quieren; como expresó Marrades (2017a): "La maternidad "comprada" reduce a la mujer a un recipiente reproductivo" (p. 223). En el contrato no está cediendo el cuerpo para salvar una vida o hacer posible el derecho a la vida o la salud de otra persona, sino que utiliza el cuerpo de una mujer, instrumentalizándolo tanto a ella como a su vida durante un tiempo, con el fin de satisfacer el deseo de otras personas (Fernández, 2017; Marrades, 2017a). Además, el Parlamento Europeo, como se ha mencionado anteriormente, condenó en el 2015 en su Informe Anual sobre los derechos humanos y la democracia en el mundo y política de la UE al respecto (punto 115) a la gestación subrogada por considerarla "contraria a la dignidad humana de la mujer, ya que su cuerpo y sus funciones reproductivas se utilizan como materia prima" (Fernández, 2017, p. 36; Fernández, 2019, p. 369; Alés, 2020, p. 59; Ruiz, 2020, p. 331). 
De lo contrario, la renuncia a los derechos derivados de la filiación reflejada en el contrato es especialmente pertinente. Es porque a las mujeres les ha resultado muy difícil obtener derechos como empezar a renunciar (Marrades, 2017a), y también porque la dignidad constituye la base de todos los derechos y si se ven afectadas, también amenaza la dignidad de la mujer.

Por último, la CE (1978) establece que "toda persona tiene derecho a la vida y a la integridad física y moral” (art. 15), un derecho que está en peligro en esta práctica. Por un lado, existen riesgos físicos derivados del proceso de gestación y parto y, por otro lado, existe un componente emocional, ya que, aunque sea involuntariamente, la mujer puede crear un vínculo con el bebé. En esta última línea se compromete a disociar y pensar en el útero como un instrumento, la mujer subrogada debe ser capaz de deshumanizar el proceso para no sufrir (Marrades, 2017a), y de esta manera sufre una agresión a su integridad moral.

Después de todo, se considera que la gestación subrogada es una acometida contra la dignidad de la mujer, ya que viola este derecho instrumentalizándolo, obligándola a renunciar a los derechos e implicando una queja sobre su integridad moral y física.

La dignidad del menor, que también se ve afectado, será tratada en el punto superior de interés del menor y su protección.

\section{- El Derecho al propio cuerpo}

Como dice Redondo (2017) "la cosificación del cuerpo femenino ha sido una constante histórica y la ratificación de la propiedad sobre el propio cuerpo es una reivindicación tradicional de las diferentes corrientes feministas" (p. 132). Podemos ver esto en el movimiento feminista con eslóganes como "Mi cuerpo, mis reglas" o "Mi cuerpo, mi decisión", apostando por el empoderamiento femenino y la emancipación a través de la toma de decisiones en el propio cuerpo.

Así, desde el sector a favor de la gestación subrogada aferrándose a esta teoría y reivindica la propiedad del propio cuerpo y la libertad de utilizarlo libremente para dar a luz al hijo de otras personas, por ejemplo, Martín (2009), apela a "la libertad de las mujeres que 
deciden ser madres subrogadas para utilizar su cuerpo para lo que consideren apropiado, poder elegir y asumir la responsabilidad de sus actos libremente" (pp. 7-8). Esto implica entender que la relación entre el ser humano y su cuerpo tiene sentido de propiedad, pudiendo tenerla en determinadas circunstancias (Redondo, 2017), como podría ser participar en un contrato de gestación subrogada.

Es necesario tener en cuenta lo que se dice en el ordenamiento jurídico del Estado español sobre la propiedad para ver si el cuerpo sería considerado o no como posesión. La CE (1978) establece que "se reconoce el derecho a la propiedad privada y a la herencia" (art. 33.1) y el Código Civil (1889) define la propiedad como "el derecho a disfrutar y disponer de algo, sin más limitaciones que las establecidas en las leyes" (art. 348). Hasta entonces, la suposición inicial parecería aceptable; Sin embargo, de acuerdo con los artículos 334 a 337 del Código Civil (1889), el cuerpo humano no sería un mueble o propiedad y, por lo tanto, de conformidad con el artículo 333, no puede estar "sujeto a apropiación" (Código Civil, 1889). En consecuencia, no habría derecho al propio cuerpo.

También hay que tener en cuenta que muchos de los contratos de gestación subrogada imponen a las mujeres un cierto estilo de vida para garantizar que el proceso se lleve a cabo de la manera que consideren correcto, al mismo tiempo que podrían verse obligadas a pasar por un aborto o prevenir esta práctica incluso si a la mujer subrogada le gustaría, sin ir más lejos. Estos hechos impiden la libre disposición del cuerpo a la mujer gestante, por lo que se ve una contradicción a la que se reclama un derecho para obtener la hija deseada, mientras que este derecho se coarta una vez que la mujer ha firmado el contrato.

En resumen, se puede concluir que la exigencia del derecho al propio cuerpo en este caso viola otros derechos como el derecho a la integridad física y moral, el derecho a la dignidad de la persona o la libertad de acción o de movimiento. De este modo, aunque el derecho al propio cuerpo debe ser reivindicado para luchar contra la opresión de las mujeres, la defensa de este derecho no puede sostenerse para llevar a cabo esta práctica cuando la afirmación de esto se basa en una tergiversación del mismo (Contreras, 2020). 


\section{- El interés superior del menor}

La Ley Orgánica 1/1996, de 15 de enero, de Protección Jurídica del Menor, de modificación parcial del Código Civil y de la Ley de Enjuiciamiento Civil, modificada por la Ley Orgánica 8/2015, de 22 de julio, de modificación del sistema de protección de menores y adolescentes, establece en su artículo 2.1 que el menor tiene derecho a que su interés superior se tenga en cuenta, se valore y se considere primordial en las acciones y decisiones que se tomen y que le afecten.

Ello se traduce tanto en el ámbito público como privado.

Se prima el interés superior del menor en las medidas que sean adoptadas por parte tanto de instituciones públicas, privadas, tribunales y órganos legislativos. Ese interés será preferente a cualquier otro interés en juego.

Hemos de tener en cuenta que el menor, como sujeto especialmente vulnerable, cuyo interés superior siempre debe de prevalecer, sea cual sea el contexto en el cual se produzca el conflicto que le pueda afectar, no siempre dispone de unas medidas las cuales puedan aplicarse y sean consideradas adecuadas para ello. Y ello no solo en el caso de la gestación subrogada, sino también es la futura integración del menor dentro de la sociedad, hasta que se considere como adulto con la plena capacidad de obrar, contemplando los supuestos de la emancipación (Ramón, 2016).

Sin embargo, como defendieron los magistrados en la STS 247/2014, el interés superior del menor es "un concepto jurídico indeterminado" y también "controvertido", cuya aplicación debe hacerse de manera que complemente la ley cuando no llega, pero que no es expresamente contraria a ella. Por lo tanto, hay un conflicto alrededor del interés superior del menor en casos de gestación suplente (Sales, 2019; Hernández, 2020).

Uno de los centros del conflicto es la identidad del menor nacido a través de gestación subrogada. En el ámbito del derecho, según la Gran Enciclopedia Catalana (GEC, 1980), la identidad se define como la "Personalidad Civil de un individuo", que consiste en los datos que diferencian a una persona de cualquier otra, por ejemplo, 
los que se recogen en el Registro Civil. En este sentido, dado que no está permitida la inscripción de menores nacidos por gestación subrogada en España, se argumenta que la identidad de estos se ve afectada — protegida por el interés superior del menor-; además, con el artículo 7 de la Convención sobre los Derechos del Niño, el cual determina que el niño nacido debe estar registrado inmediatamente después del nacimiento y debe tener un nombre, nacionalidad, conocer a los padres y ser cuidada por ellos (Ramón, 2014).

Por otro lado, también en lo que respecta a la identidad, el artículo 39.2 de la Constitución Española de 1978 dice que "la ley permitirá la investigación de la paternidad" (Valvidares, 2020, p. 137), es decir, el derecho de las hijas a saber quiénes son los padres, a conocer sus orígenes; un derecho que también podría ser protegido, por extensión, por el Código Civil (1889, art, 180.6), que determina el derecho a conocer los datos sobre el origen biológico, y que se debe prestar por parte de las entidades públicas competentes los servicios de asesoramiento y ayuda para cumplir con ese propósito.

Sin embargo, en muchos contratos de gestación subrogada, con el objetivo de desvincular totalmente a la mujer subrogada y donante en caso de que hubiera, se establece que esta información no estará disponible, negando a los menores este derecho, también cubierto por la Convención sobre los Derechos del Niño (López y Aparisi, 2012), siendo considerada una cláusula contraria a la ley.

También se entiende que el interés superior del menor debe proteger su dignidad. Sin embargo, el STS 247/2014 afirma que la comercialización de la filiación del menor — tratada posteriormente — viola la dignidad del menor convirtiéndola en objeto de tráfico comercial. Al instrumentalizar al menor, convirtiéndose en un producto del deseo que serán comprados por los comitentes, deshumaniza y barre contra su dignidad. Por otro lado, en esta misma línea, el interés superior del menor debe establecer medidas que prevengan y enjuicien efectivamente la trata de niñas, hecho que pueda derivarse fácilmente de la gestación subrogada o que pueda aprovecharse de los contratos que se llevan a cabo para blanquear. 
Así, el interés superior del menor pone en una situación difícil, ya que una vez nacida el hijo debe garantizar el registro civil para cumplir con el artículo 7 de la Convención de los Derechos del Niño (ONU, 1989). Sin embargo, hay otra serie de consecuencias ya discutidas que también deben ser protegidas por la ley y la mejor manera de proteger el interés superior del menor sería separar el origen de las consecuencias.

\section{Aspectos éticos}

\section{- La comercialización de seres humanos}

Como se ha analizado anteriormente, en la Sentencia STS 247/2014 del Tribunal Supremo, los magistrados expresan que esta práctica comercializa gestación y filiación y, de este modo, también al menor nacido como consecuencia del contrato. Esta declaración se da porque el proceso se lleva a cabo a cambio de una cierta cantidad de dinero, un pago que, según el sector que defiende la gestación subrogada, es sólo una forma de pagar a la mujer subrogada por los riesgos e implicaciones del proceso (Martín, 2009; Ortega, 2020).

Sin embargo, según la CEI, la comercialización está "poniendo (un producto) a disposición de los consumidores en el comercio", y ciertamente ha generado todo un mercado en torno a esta práctica en la que se pone a disposición de los consumidores -los comitentesun producto - la gestación y la hija-. Hay una demanda por parte de los comitentes y una oferta de las mujeres embarazadas, por lo general a través de empresas o agencias intermediarias. Con estos organismos se ha ampliado la oferta, a través de la organización del traslado del cliente al país de compra, servicios médicos y jurídicos, posibilidad de alguna eugenesia o elección de características de las mujeres embarazadas y de los donantes (Nuño, 2016). Además, como cualquier otro negocio en el libre mercado de la globalización, aprovechan las peores condiciones en los países "en desarrollo", dándose el llamado "turismo reproductivo", con el fin de reducir los costos, aumentar los beneficios y la satisfacción del cliente (Nuño, 2016, p. 700, p. 687; García y Cayuela, 2020, p. 37). Con todo esto, 
según Guerra-Palmero (2018), podríamos hablar de neocolonialismo reproductivo e incluso de la trata de mujeres con fines de explotación reproductiva asimilando el papel de los organismos a figuras de otras actividades como el proxenetismo.

Teniendo todo esto en cuenta, se podría decir que existe una comercialización de la mujer, pero no se puede olvidar que el objeto del contrato no es alquilar el cuerpo de la mujer para llevar a cabo una gestación sin más, el objetivo principal es obtener descendencia. De esta manera, el producto que realmente se está comprando es el ser humano que nace de la gestación sustituta, por lo que se le da una comercialización de menores. Se puede llamar con estos términos en virtud del Protocolo facultativo de la Convención sobre los Derechos del Niño relativo a la venta de niños, la prostitución infantil y la utilización de niños en la pornografía (ONU, 2000), que entró en vigor el 18 de enero de 2002, establece en el artículo 2 qué se entiende por venta de niños, por prostitución infantil y por pornografía infantil.

Ningún ser humano puede ser considerado un producto básico ni los cuerpos de las mujeres pueden ser nicho de mercado (Nuño, 2016), como se ha discutido en el punto del derecho al propio cuerpo, estos no son una propiedad y, por lo tanto, no pueden ser objeto de venta, no son nada extra commercium. Esto también deriva, según el Código Civil (1889), que no pueden ser objeto de contrato, ya que sólo "todas las cosas que no están fuera del comercio del hombre pueden ser contraídas" (art. 1271).

También hay que añadir que, como resultado de esta comercialización, se crea una "ciudadanía censal” (STS 247/2014), ya que sólo aquellos con un alto poder adquisitivo pueden acceder a esta práctica que les permite sufragar los gastos involucrados, lo que refuerza las desigualdades de clase.

- El principio de autonomía de la voluntad

Según Kant (1785): 
La autonomía de la voluntad es el estado por el cual se trata de una ley en sí misma, independientemente de cómo se constituyan los objetos de deseo. En este sentido, el principio de autonomía no es más que elegir de tal manera que las máximas de la elección de querer se incluyan al mismo tiempo que las leyes universales (p. 22).

Por lo tanto, se podría decir que la autonomía representa la independencia en la toma de decisiones, sin suposiciones de ningún tipo; y en el caso de la gestación subrogada este principio podría tratarse en dos sentidos clave: antes de firmar el contrato y una vez firmado.

En el primer caso, apela a la autonomía de la mujer subrogada y al consentimiento informado para defender esta práctica, argumentando que firma el contrato libre y conscientemente. Sin embargo, en este punto, más que en cualquier otro, se necesita un análisis con una perspectiva de clase; Así que, como se plantea Sandel (Nuño, 2016), "¿hasta qué punto somos libres cuando elegimos el libre mercado?" (p. 691). La libertad puede condicionarse por necesidad y es necesario tener en cuenta la posición que cada uno ocupa en el mercado (Marrades, 2017b). Los comisionados se encuentran en situaciones adineradas, pudiendo pagar los gastos que implica contratar a una mujer para tener una hija, mientras que las mujeres sustitutas, por otro lado, se encuentran en situaciones peores, a menudo de precariedad económica y/o presión social y/o familiar. Por lo tanto, para estos últimos, las decisiones están condicionadas por estos hechos, aunque se declara que se hace voluntaria y libremente es el contexto en el que se experimenta que impulsa a tomar esta decisión. Del mismo modo, ha habido debate en el campo de la prostitución, ¿cuántas mujeres realmente libres decidirían ejercer la prostitución? Pero, ¿puedes ir más allá, si no necesitas el salario del trabajo para poder vivir, cuántas personas trabajarían con las condiciones de trabajo actuales?

Por otra parte, en el segundo caso cabe señalar que se da la misma contradicción que con la reivindicación del derecho al propio organismo del sector que defiende la gestación subrogada. Apela al consentimiento libre y consciente de la mujer subrogada para que firme el contrato para dar a luz a un bebé para los huéspedes, mientras que este mismo contrato cancela su autonomía en el mismo sentido que 
se explicó anteriormente, cuando la mujer deja de tener una decisión sobre sí misma. La opción de jubilarse o rechazarse siempre debe estar disponible en los contratos para no suspender la autonomía de la persona (Guerra-Palmero, 2017), y sin embargo no lo es.

En consecuencia, contrariamente a lo que defiende un sector de la sociedad, se puede afirmar que el principio de autonomía de la voluntad no se respeta en esta práctica, teniendo en cuenta que nunca se puede respetar viviendo bajo el capitalismo.

\section{Propuestas DE Futuro}

\section{Proposiciones de Ley}

Existe una corriente que apuesta por la regulación de la gestación subrogada, de hecho, la Asociación para la Gestación Subrogada en España sostiene que los problemas derivados de la gestación subrogada son realmente generados por la falta de regulación (Matia, 2019). Por esta razón, han surgido varios proyectos de ley (César, 2019; Ferrer, 2019b), de los cuales dos se discuten a continuación.

En 2013, el abogado Joan Cerdá, redactó una propuesta de la Ley de Subrogación para la Gestación subrogada para la Asociación para la Gestación Subrogada en España. Algunos de los aspectos más destacados son los siguientes (Matia, 2019):

1. La gestación subrogada representa la última opción, después del agotamiento o de ser incompatible con las otras posibilidades de tener hijas.

2. La mujer subrogada debe ser mayor de 18 años, haber tenido una hija previamente y estar en buenas condiciones psicofísicas. Además, debe estar inscrita en el Registro Nacional del Embarazo Suplente.

3. No es lucrativo, es decir, es altruista. La compensación económica establecida sólo compensa las molestias físicas, los gastos de viaje y de mano de obra y el beneficio cesante inherente al procedimiento; además, debe garantizar las condiciones adecuadas para las mujeres sustitutas durante los estudios y tratamientos pregestacional, la gestación y el posparto. 
4. La parte subrogante puede ser una persona sola o una parella.

5. Si se produce alguna de las causas contenidas en la Ley Orgánica 2/2010, la mujer subrogada podrá decidir interrumpir el embarazo, devolviendo el dinero.

6. Una vez que el nacimiento tiene lugar, el niño pasa a estar a cargo de los comitentes, que deben inscribirlo en el Registro Civil. Además, una vez que la transferencia de embriones haya tenido lugar, no podrán impugnar la filiación.

Por otro lado, el Grupo Parlamentario Ciudadano presentó un Proyecto de Ley 145-1 (2017) que regula el derecho a la gestación subrogada, actualizándolo y representándolo en 2019. Afirman que hoy "la gestación subrogada constituye una realidad tanto en España como en los países que nos rodean" (p. 3) y que "es bien sabido, de hecho, que los cambios sociales necesariamente implican cambios en las reglas" (p. 3), por esta razón presentan el proyecto de ley a las Cortes Generales.

Como se explica en la exposición de motivos, el proyecto de ley está organizado en siete (7) capítulos. El primero incluye las disposiciones generales, las definiciones necesarias, los requisitos que deben cumplirse y el carácter altruista de esta práctica. El segundo regula los derechos y requisitos que deben cumplir los participantes, además del contenido y la formalización del contrato. El tercero se refiere a la fertilización y el parto, aparte de la filiación y lo que sucedería en caso de premoriencia. El cuarto crea el Registro Nacional de Gestación Subrogada; mientras que el quinto establece las condiciones a cumplir por los centros que pueden llevar a cabo la gestación subrogada. El sexto se ocupa del asesoramiento y la orientación del uso de la gestación subrogada, responsabilidad de la Comisión Nacional de Reproducción Humana Asistida. Por último, el séptimo capítulo incluye las violaciones y sanciones por conductas que sean ordinarias según lo establecido por esta Ley. También incluye una disposición única de derogación para revocar todas las disposiciones reglamentarias opuestas a la Ley 14/2006 y, en particular, el artículo 10. 
Las principales diferencias con el proyecto de ley redactado por Joan Cerdá aparecen en los requisitos que debe cumplir la mujer subrogada que, por ejemplo, debe tener más de veinticinco años y no haber sido una mujer subrogada en más de una ocasión anterior; así como la regulación de los centros de salud autorizados para llevar a cabo el embarazo suplente y el régimen de infracciones y sanciones (Matia, 2019).

Como lo expresa Pasquau (2017), aunque se refiere a la Proposición de Ley presentada por Ciudadanos en 2017 pero aplicable a la de 2019, lo que regula esta ley "es un contrato civil en virtud del cual una mujer presta un servicio corporal a cambio de un precio" (párr. 3), aunque por este "precio" se utiliza el eufemismo de la "compensación económica" (párr. 5). De esta manera, "consagraría una explotación económica del cuerpo de mujeres pobres" (Pasquau, 2017, párr. 1), abriendo también la posibilidad de regular el mercado de la venta de órganos.

Los efectos que plantea la propuesta no sólo son a efectos de filiación, sino también se plantean otros como son los de ámbito fiscal (Hernández, 2020; Martínez, 2019), laboral (Rodríguez, 2019; Tomás, 2019), y penal (Lledó, 2019b).

\section{ConClusiones}

Como se ha visto a lo largo del trabajo, el ordenamiento jurídico en España, a pesar de no permitir la gestación subrogada, da lugar a cierta incertidumbre legislativa, ya que deja lagunas a través de las cuales puede salvar la prohibición. Sin embargo, no todo el mundo puede burlarse del sistema, pero sólo aquellos con un alto poder adquisitivo podrán acceder a esta práctica y, además, lo harán a expensas de otras personas con peores condiciones de vida (Martín, 2019).

Por lo tanto, la subrogación es otra expresión de lucha de clases donde se refuerza el poder de la clase dominante. Se ha visto cómo esta práctica, a través de la comercialización, el control sobre los cuerpos de las mujeres y la defensa de la falsa autonomía, ataca los derechos de las mujeres subrogadas y menores nacidos, representando un ataque a su dignidad. Esta manifestación de la lucha de clases también se observa en un momento en que el capital tiene la capacidad de 
convertir los deseos en derechos y el deseo de tener hijos se convierte en una realidad sólo para aquellos que pueden permitírselo.

Una solución parcial para estas correcciones, desde esta perspectiva, sería prohibir la gestación subrogada de manera eficiente y eficaz (Fernández, García, González y Gómez, 2020; Hermida, 2019; Vicandi, 2019).

Sin embargo, no se puede apostar por una prohibición basada en medidas punitivas, mientras que el resto sigue siendo lo mismo. Por un lado, hay que reconsiderar la legislación vigente para encontrar la mejor fórmula y evitar grietas salvables. Por otro lado, también se deben ofrecer alternativas reales a aquellas mujeres que son impulsadas a alquilar sus cuerpos para este fin cuando no ven otras alternativas factibles. Por último, esta solución también pasa porque los procesos de adopción se faciliten sin perder de vista el interés superior de los menores, proporcionando así una alternativa real a aquellos que quieren tener hijos, una opción que no pasaría por la comercialización de los seres humanos. Con este último, garantizaría el interés superior de los menores que no tienen familia, ya que, como se mencionó anteriormente, se eliminarían todos los problemas derivados de la gestación subrogada y los esfuerzos podrían centrarse en el cuidado de estos menores.

Más allá de eso, para cerrar se considera que se han cumplido los objetivos establecidos en este trabajo, ya que se ha podido hacer un análisis cuidadoso de la normativa actual aplicada a la gestación subrogada y de las cuestiones éticas que plantea, por lo que nos ha permitido crear una opinión al respecto. Además, que se ha expuesto la situación para que los recursos necesarios estén disponibles para el lector para que pueda generar su propio análisis.

Finalmente, viendo todo lo que se ha detallado en este estudio y recuperando la pregunta que se planteó en la introducción, ¿todo lo científicamente posible es éticamente aceptable?". No todo lo científicamente posible es éticamente aceptable, en este caso, la gestación subrogada. No es aceptable porque conculca los derechos de las mujeres y los menores, refuerza las diferencias de clase y no es más que una expresión de la dureza del capitalismo. 


\section{REFERENCIAS}

Abellán-García, F. (2016). Gestación por sustitución: dificultades para mantener la prohibición en España. Revista de Derecho, Empresa y Sociedad, (9), 60-77. Disponible en https:// libros-revistas-derecho.vlex.es/vid/gestacion-sustituciondificultades-mantener-672194273

Alés, M. (2020). La dignidad humana y el derecho de disposición sobre el propio cuerpo. Reflexiones a partir del rechazo de tratamientos médicos y los acuerdos de maternidad subrogada. Dikaion: revista de actualidad jurídica, 29(1), 39-65. https://doi.org/10.5294/dika.2020.29.1.2

Álvarez, H. (2019). Aspectos civiles más relevantes de la gestación por subrogación: la inscripción en el Registro Civil. Revista jurídica de Castilla y León, (49), 85-106. Recuperado de https://www.jcyl.es/web/jcyl/AdministracionPublica/es/ Plantilla100Detalle/1131978346397/_/1284892018990/ Redaccion

Andreu, B. (2019). Una nueva vuelta de tuerca en la inscripción de menores nacidos mediante gestación subrogada en el extranjero: La instrucción de la DGRN de 18 de febrero de 2019. Actualidad jurídica iberoamericana, 10(2), 6485. Recuperado de http://www.revista-aji.com/wp-content/ uploads/2019/06/64-85.pdf

Avilés, B. y Ramón, F. (2019). La donación de óvulos en la reproducción asistida: riesgos y responsabilidad. Ius et Scientia, 5(2), 11-54. https://doi.org/10.12795/IESTSCIENTIA.2019.i02.03

Barcelona FIV. (2012). ¿Sabías cuándo se realizó la primera inseminación? [blog]. Recuperado de https://barcelonaivf.com/ es/blog/general/sabias-cuando-se-realizo-la-primera-inseminacion 
Belinchón, M. R. (2019). Gestación subrogada: especial referencia a la situación y a la voluntad de la mujer para prestar el consentimiento en el contrato de gestar para otro. En, A. Gutiérrez (Coord.), Gestación subrogada: Principales cuestiones civiles, penales, registrales y médicas: su evolución y consideración (1988-2019) (pp. 167-194). Madrid: Dykinson.

Benítez, I. F. (2019). Maternidad subrogada e interrupción voluntaria del embarazo. En, A. Gutiérrez (coord.), Gestación subrogada: Principales cuestiones civiles, penales, registrales y médicas: su evolución y consideración (1988-2019) (pp. 605-624). Madrid: Dykinson.

Biffi, M. y Marques, T. M. (2017). Projeto de ter filhos: uma revisão da literatura científica nacional e internacional. Temas em Psicologia, 25(1), 207-220. https://doi.org/10.9788/ TP2017.1-14Pt

Boada, M. y Coroleu, B. (2010). Aspectos medicobiológicos de la subrogación uterina. En, M. Boada, La subrogación uterina: análisis de la situación actual (pp. 10-23). Barcelona: Ed. Fundació Víctor Grífols i Lucas. Recuperado de https:// www.fundaciogrifols.org/documents/4662337/4689123/intetic3.pdf/d0ab3ef6-0eff-4d97-a14e-d6d32470d1f1

Cañal, L., Cocina, V., Ardines, M., Carro, N. y Torre, A. (2019). Derecho a la parentalidad: sustrato de la gestación subrogada. En, M. Nuñez y P. Jiménez, Mujer sujeto u objeto de derechos reproductivos: derechos de los menores y maternidad por sustitución (pp. 167-184). Valencia: Tirant lo Blanch.

Cardona, O. (2019). La gestación subrogada: concepto. El artículo 10 LTRHA. En, A. Gutiérrez (Coord.), Gestación subrogada: Principales cuestiones civiles, penales, registrales y médicas: su evolución y consideración (1988-2019) (pp. 237-246). Madrid: Dykinson. 
Casado, M. e Ibáñez, M. (2014). Reflexiones legales y éticas en torno a la maternidad subrogada. Revista Española de Medicina Legal, 40(2), 59-62. https://doi.org/10.1016/j. reml.2013.06.008

Castellanos, J. (2019). Análisis de la maternidad subrogada como nueva tecnología en el ámbito biomédico y jurídico-filosófico: avance técnico, retroceso humano. Revista sobre la infancia y la adolescencia, (17), 62-80. https://doi.org/10.4995/ reinad.2019.11933

César, J. (2019). El debate en torno a la gestación por subrogación en el parlamento. En, A. Gutiérrez (Coord.), Gestación subrogada: Principales cuestiones civiles, penales, registrales y médicas: su evolución y consideración (1988-2019) (pp. 119-130). Madrid: Dykinson.

COHADIP. (1993). Convenio de La Haya relativo a la Protección del Niño y a la Cooperación en materia de Adopción Internacional. [Online]. Recuperado de https://www.oas.org/dil/ esp/Convenio_Haya_Proteccion_del_Nino_Cooperacion_ en_Materia_Adopcion_Internacional_Espana.pdf

Contreras, F. J. (2020). Contra la gestación subrogada. En, A. Sánchez (Coord.), Dignidad y vida humana: eutanasia, gestación subrogada y transhumanismo (pp. 361-366). Cizur Menor: Thomson Reuters Aranzadi.

Díaz, J. M. (2019). La gestación por sustitución ante el registro civil español. Evolución de la doctrina de la DGRN y de la jurisprudencia española y europea. Revista de Derecho Civil, 6(1), 53-131. Recuperado de https://www.nreg.es/ojs/index. $\mathrm{php} / \mathrm{RDC} / \mathrm{article/view/401}$

Engels, F. (1884). El origen de la familia, la propiedad privada y el Estado. Madrid: Alianza Editorial.

Enguer, P. y Ramón, F. (2018). Dilemas bioéticos y jurídicos de la reproducción asistida en la sociedad actual en España. Revista Latinoamericana de Bioética, 18(34), 104-135. https:// doi.org/10.18359/rlbi.3160 
Fernández, A. (2020). Por qué es nulo el contrato de gestación por sustitución y qué efectos se derivan de dicha nulidad. En, A. Sánchez (Coord.), Dignidad y vida humana: eutanasia, gestación subrogada y transhumanismo (pp. 305-330). Cizur Menor:Thomson Reuters.

Fernández, O., García, L., González, A. y Gómez, S. (2020). Gestación subrogada: ¿Regulación actual o legalización? En, M. Nuñez y P. Jiménez, Mujer sujeto u objeto de derechos reproductivos: derechos de los menores y maternidad por sustitución (pp. 185-195). Valencia: Tirant lo Blanch.

Fernández, P. (2019). La gestación subrogada y la jurisprudencia del Tribunal Europeo de Derechos Humanos. En, A. Gutiérrez (Coord.), Gestación subrogada: Principales cuestiones civiles, penales, registrales y médicas: su evolución y consideración (1988-2019) (pp. 369-379). Madrid: Dykinson.

Fernández, P. I. (2017). Gestación subrogada, ¿cuestión de derechos? Dilemata, (26), 27-37. Disponible en https://www.dilemata.net/revista/index.php/dilemata/article/view/412000171

Ferrer, M. P. (2019). La gestación subrogada en la legislación española. Ley 35/1988, de 22 de noviembre, sobre técnicas de reproducción asistida y la ley 14/2006, de 26 de mayo, sobre técnicas de reproducción humana asistida. En, A. Gutiérrez (Coord.), Gestación subrogada: Principales cuestiones civiles, penales, registrales y médicas: su evolución y consideración (1988-2019) (pp. 25-28). Madrid: Dykinson.

Ferrer, M. P. (2019b). La posición de los distintos grupos parlamentarios y la pl presentada por el gp ciudadanos sobre la gestación subrogada (BOCG $\mathrm{n}^{\circ}$ b-145-1). En, A. Gutiérrez (Coord.), Gestación subrogada: Principales cuestiones civiles, penales, registrales y médicas: su evolución y consideración (1988-2019) (pp. 105-118). Madrid: Dykinson. 
Gálvez, A. (2019). ¿Sigue siendo nulo en España el contrato de gestación subrogada? Una duda razonable. Diario La Ley, (9444). Disponible en https://diariolaley.laleynext.es/ dll/2019/06/26/sigue-siendo-nulo-en-espana-el-contratode-gestacion-subrogada-una-duda-razonable

García, D. J. y Cayuela, S. (2020). Aspectos bioéticos de la gestación subrogada comercial en relación con la madre portadora: el conflicto entre los principios de justicia y autonomía. Revista de filosofía, 45(1), 27-46. https://doi.org/10.5209/ resf.57976

García, C. (2014). El ámbito familiar en Roma y hoy. Especial mención a la situación de las mujeres. Oviedo: Universidad de Oviedo.

GEC. (1989). Gran Enciclopedia Catalana. Barcelona: Grup Enciclopèdia Catalana.

Guerra-Palmero, M. J. (2017). Contra la llamada gestación subrogada. Derechos humanos y justicia global versus bioética neoliberal. Gaceta Sanitaria, 31(6), 535-538. https://doi. org/10.1016/j.gaceta.2017.05.009

Guerra-Palmero, M. J. (2018). Contra la mercantilización de los cuerpos de las mujeres. La "gestación subrogada" como nuevo negocio transnacional. Dilemata, (36), 39-51. Disponible en https://www.dilemata.net/revista/index.php/dilemata/article/view/412000172

Gutiérrez, A. (2019). El artículo 10 de la ley 14/2006 y su análisis comparativo con lo dispuesto en otras legislaciones permisivas: especial atención a EE.UU. y reflexión sobre cláusulas habituales en estos contratos. En, A. Gutiérrez (Coord.), Gestación subrogada: Principales cuestiones civiles, penales, registrales y médicas: su evolución y consideración (1988-2019) (pp. 225-236). Madrid: Dykinson.

Hermida, B. (2019). ¿Es necesaria una regulación sobre gestación subrogada? En, M. García (Dir.), Mujer, maternidad y Derecho (pp. 685-702). Valencia: Tirant lo Blanch. 
Hernández, F. (2020). La compensación económica resarcitoria en la proposición de ley reguladora del derecho a la gestación por subrogación y su fiscalidad. Revista sobre la infancia y la adolescencia, (18), 60-68. https://doi.org/10.4995/reinad.2020.13067

Hernández, L. (2020). Gestación por sustitución internacional e interés superior del menor. Revista de derecho político, (197), 181-210. https://doi.org/10.5944/rdp.107.2020.27187

Herrán, A. I. (2019). Aproximación ética y jurídica a la gestación subrogada: a vueltas con el conflicto entre derechos y deseos. En, A. Gutiérrez (coord.), Gestación subrogada: Principales cuestiones civiles, penales, registrales y médicas: su evolución y consideración (1988-2019) (pp. 267-302). Madrid: Dykinson.

IEC. (2020). Subrogado. [Online]. Disponible en https://www.iec. cat/activitats/entrada.asp

Itaia. (Abril 14, 2019). Reflexión teórico-política de la problemática de género. [Online]. Disponible en https://itaia. eus/2018/12/30/familiari-buruzko-zenbait-apunte-apuntes-sobre-la-familia/

Kant, I. (1785). Fundamentación de la metafísica de las costumbres. Madrid: Espasa Calpe.

Lamm, E. (2016). Una vez más sobre gestación por sustitución, porque sin marco legal se siguen sumando violaciones a derechos humanos. Ars Iuris Salmanticensis, 4(1), 61107. Disponible en https://revistas.usal.es/index.php/ais/ article/view/14368

Lamm, E. (2013). Gestación por sustitución. Ni maternidad subrogada ni vientres de alquiler. Barcelona: Publicacions i Edicions de la Universitat de Barcelona.

Lara, F. (1982). Código de Hammurabi. Madrid: Editora Nacional. 
Lázaro, C. (2019). El concepto de persona como elemento clave de la identidad europea: el caso de la maternidad subrogada. Cuadernos Europeos De Deusto, (2), 189-201 https://doi. org/10.18543/ced-02-2019pp189-201

López, J. y Aparisi, Á. (2012). Aproximación a la problemática ética y jurídica de la maternidad subrogada. Cuadernos de bioética, 23(78), 253-268. Recuperado de http://aebioetica. org/revistas/2012/23/78/253.pdf

López, R. (2019). La gestación por sustitución altruista no elimina el aspecto contractual de la gestación del así nacido. Revista jurídica de Castilla y León, (49), 107-152. Recuperado de https://www.jcyl.es/web/jcyl/AdministracionPublica/es/ Plantilla100Detalle/1131978346397/_/1284892020584/ Redaccion

Lledó, F. (2019a). La filiación en la gestación subrogada: el estado de la cuestión (1998-2019). En, A. Gutiérrez (Coord.), Gestación subrogada: Principales cuestiones civiles, penales, registrales y médicas: su evolución y consideración (19882019) (pp. 29-74). Madrid: Dykinson.

Lledó, I. (2019b). Delitos relativos a la filiación y maternidad por sustitución: reflexiones de Lege Data y de Lege Ferenda. En, A. Gutiérrez (Coord.), Gestación subrogada: Principales cuestiones civiles, penales, registrales y médicas: su evolución y consideración (1988-2019) (pp. 625-672). Madrid: Dykinson.

Lledó, F. y Gutiérrez, A. (2018). La gestación subrogada: luces y sombras de la legislación actual. Su prohibición versus la posibilidad de una admisión de supuestos en el futuro. En, M. Romero, Nuevos Horizontes y perspectivas para el Derecho en el siglo XXI (pp. 183-204). Cizur Menor: Aranzadi Thomson Reuters. 
Lledó, F. y Monje, O. (2020). La gestación por sustitución: su evolución desde la primera Ley 35/1988, de 22 de noviembre hasta el momento presente diciembre 2019. Revista de Derecho, Empresa y Sociedad (REDS), (15), 16-25. Recuperado de https://www.dykinson.com/revistas/revista-dederecho-empresa-y-sociedad/1170/

Lluch, C. y Ramón, F. (2017). El caso Moore y la prestación del consentimiento informado en investigación médica. Revista Derecho y Salud, 27(2), 58-87. Disponible en https:// www.ajs.es/index.php/es/index-revista-derecho-y-salud/ volumen-27-numero-2-2017/el-caso-moore-y-la-prestaciondel

Magariños, V. (2019). Reflexiones sobre la maternidad subrogada. En, A. Gutiérrez (Coord.), Gestación subrogada: Principales cuestiones civiles, penales, registrales y médicas: su evolución y consideración (1988-2019) (pp. 75-104). Madrid: Dykinson.

Marabel, J. J. (2019). El bioderecho ante el reto de la gestación subrogada. Revista de Derecho UNED, (24), 203-230. https://doi.org/10.5944/rduned.24.2019.25434

Marrades, A. (2017a). La gestación subrogada en el marco de la Constitución Española: una cuestión de derechos. Estudios de Deusto, 65(1), 219-241. Recuperado de http://revista-estudios.revistas.deusto.es/article/view/1320

Marrades, A. (2017b). El debate sobre la gestación subrogada en España: entre el deseo, la dignidad y los derechos. Revista Europea de Derechos Fundamentales, (30), 153-177. Recuperado de_http://roderic.uv.es/handle/10550/65598

Martín, M. (2019). La supuesta donación de la capacidad reproductiva en la gestación por sustitución. Revista Derecho y Salud, 29(1), 169-179. Disponible en http://www.ajs.es/ es/index-revista-derecho-y-salud/volumen-29-extraordinario-2019/la-supuesta-donacion-la-capacidad 
Martín, J. (2009). Maternidad subrogada: una práctica moralmente aceptable. Análisis crítico de las argumentaciones de sus detractores. Fundación Foro, 1-18. Recuperado de https://www.fundacionforo.com/pdfs/maternidadsubrogada.pdf

Martínez, V. L. (2019). Procedencia de las prestaciones de maternidad en la gestación subrogada. e-Revista Internacional de la Protección Social, 4(1), 41-64. https://doi.org/10.12795/ e-RIPS.2019.i01.04

Matia, F. J. (2019). ¿Resulta oportuno dar un tratamiento jurídico a la gestación subrogada en nuestro país? Revista de Derecho Político, (105), 81-125. https://doi.org/10.5944/ rdp.105.2019.25269

Monje, O. (2019). La problemática de la inscripción de la filiación en supuestos de gestación subrogada: las instrucciones de la DGRN de 14 y 18 de febrero de 2019 y la posición de los órganos jurisdiccionales y del Tribunal Europeo de Derechos Humanos. En, A. Gutiérrez (Coord.), Gestación subrogada: Principales cuestiones civiles, penales, registrales y médicas: su evolución y consideración (1988-2019) (pp. 247-266). Madrid: Dykinson.

Moya, M. y Ramón, F. (2018). El diagnóstico genético preimplantacional: aspectos jurídicos en el derecho español. Revista de Derecho Privado, (34), 81-121. https://doi. org/10.18601/01234366.n34.04

Muñoz, E. (2019). Two legged wombs: surrogacy and margaret atwood's the handmaid's tale. Revista de Estudios Norteamericanos, 23, 231-248. https://doi.org/10.12795/ REN.2019.i23.11

Nuño, L. (2016). Una nueva cláusula del Contrato Sexual: vientres de alquiler. Isegoría. Revista de Filosofía Moral y Política, (55), 683-700. https://doi.org/10.3989/isegoria.2016.055.15 
ONU. ACNUDH. (2000). Protocolo facultativo de la Convención sobre los Derechos del Niño relativo a la participación de niños en los conflictos armados. [Resolución A/RES/54/263]. Recuperado de https://undocs.org/es/A/RES/54/263

ONU. ACNUDH. (1989). Convención de los Derechos del Niño. [Resolución A/RES/73/155]. Recuperado de https://undocs. org/es/A/RES/44/25

Ortega, R. (2020). La única vía para garantizar que la gestación subrogada sea éticamente correcta. Eidon: revista de la fundación de ciencias de la salud, (53), 36-46. https://doi. org/10.13184/eidon.53.2020.36-46

Palacios, M. (2019). Gestación de sustitución (1984-2019). En, A. Gutiérrez (Coord.), Gestación subrogada: Principales cuestiones civiles, penales, registrales y médicas: su evolución y consideración (1988-2019) (pp. 3-24). Madrid: Dykinson.

Pasquau, M. (agosto 6, 2017). Gestación subrogada: no es solidaridad, es mercado. CTXT. Recuperado de https://ctxt.es/ es/20170628/Firmas/13629/ctxt-gestacion-subrogadavientres-alquiler-ciudadanos.htm

RAE. (2020). Subrogado. [Online]. Disponible en https://dle.rae.es/ subrogar

Ramón, F. (2019). Del hermano medicamento o salvador a la terapia génica: cuestiones legales respecto a la situación del menor ante los nuevos avances biomédicos. Revista de Derecho, Empresa y Sociedad (REDS), 14, 69-100. Recuperado de https://www.dykinson.com/revistas/revista-dederecho-empresa-y-sociedad/1160/

Ramón, F. (2018). La monoparentalidad como nuevo modelo familiar: Acciones previstas en la legislación para la protección del menor. Actualidad civil, (11), 1-15. Disponible en http://hdl.handle.net/10251/114607 
Ramón, F. (2017). Menor y diversidad sexual. Análisis de las medidas de protección en el ordenamiento jurídico español para la identidad de género. [Colección Infancia y Adolescencia]. Valencia: Universitat Politècnica de València. Recuperado de https://n9.cl/6awrj

Ramón, F. (2016). La integración social del menor: régimen y cuestiones jurídico-civiles. Revista de Derecho Actual, I, 1-91. Recuperado de https://n9.cl/ug5gd

Ramón, F. (2014). La protección del menor en los casos de gestación por sustitución: análisis de diversos supuestos prácticos. Revista sobre la infancia y la adolescencia, (6), 38-50. https://doi.org/10.4995/reinad.2014.1664

Redondo, L. (2017). Libre disposición sobre el cuerpo: la posición de la mujer en el marco de la gestación subrogada. Eunomía. Revista en Cultura de la Legalidad, (12), 131-146. https:// doi.org/10.20318/eunomia.2017.3646

Redondo, L. (2016). Asimetría reproductiva: controversias entre el derecho a la reproducción y la gestación subrogada. Anuario de la Facultad de Derecho, (9), 49-68. Recuperado de_ https://ebuah.uah.es/dspace/handle/10017/28857

Reina Valera. (2009). El Antiguo Testamento. [Online]. Disponible en https://www.churchofjesuschrist.org/study/scriptures/ot/ title-page?lang $=$ spa

Reino de España. Audiencia Provincial de Valencia. (23 de noviembre de 2011). ECLI: ES:APV:2011:5738. [SAP V 5738/2011]. Ponente: Carlos Esparza Olcina. Disponible en https://www. poderjudicial.es/search/AN/openCDocument/3dd341d8d50 ca321b00d83e26fabfa14e01f358adb592bcd

Reino de España. Congreso de los Diputados. (8 de septiembre de 2017). Proposición de Ley reguladora del derecho a la gestación por subrogación. [Proposición de ley Núm. 145-1]. Autor: Grupo Parlamentario Ciudadano. Recuperado de https://www.congreso.es/public_oficiales/L12/CONG/ BOCG/B/BOCG-12-B-145-1.PDF 
Reino de España. Congreso de los Diputados. (10 de abril de 1986). Comisión Especial para el Estudio de la Fertilización « In vitro " y la Inseminación Artificial Humana. [Informe]. Diario de sesiones del Congreso de los Diputados No. 280. Recuperado de https://www.congreso.es/public_oficiales/ L2/CONG/DS/PL/PL_280.PDF

Reino de España. Cortes Generales. (29 de diciembre de 1978). Legislación consolidada. [Constitución Española]. BOE 311. BOE-A-1978-31229. Disponible en https://www.boe.es/eli/ es/c/1978/12/27/(1)/con

Reino de España. Jefatura del Estado. (23 de julio de 2015). Modificación del sistema de protección a la infancia y a la adolescencia. [Ley Orgánica 8/2015]. BOE 175. BOE-A-2015-8222. Disponible en https://www.boe.es/eli/es/lo/2015/07/22/8

Reino de España. Jefatura del Estado. (21 de julio de 2011). Registro Civil. [Ley 20/2011]. BOE. 175. BOE-A-2011-12628. Disponible en https://www.boe.es/eli/es/1/2011/07/21/20/con

Reino de España. Jefatura del Estado. (26 de mayo de 2006). Técnicas de reproducción humana asistida. [Ley 14/2006]. BOE 126. BOE-A-2006-9292. Disponible en https://www.boe.es/ eli/es/1/2006/05/26/14/con

Reino de España. Jefatura del Estado. (15 de enero de 1996). Protección Jurídica del Menor, de modificación parcial del Código Civil y de la Ley de Enjuiciamiento Civil. [Ley Orgánica 1/1996]. BOE 15. BOE-A-1996-1069. Disponible en https:// www.boe.es/eli/es/lo/1996/01/15/1/con

Reino de España. Jefatura del Estado. (23 de noviembre de 1995). Código Penal. [Ley Orgánica 10]. BOE 281. BOEA-1995-25444. Disponible en https://www.boe.es/eli/es/ lo/1995/11/23/10/con

Reino de España. Jefatura del Estado. (22 de noviembre de 1988). Técnicas de Reproducción Asistida. [Ley 35/1988]. BOE 282. BOE-A-1988-27108. Disponible en https://www.boe. es/eli/es/1/1988/11/22/35 
Reino de España. Ministerio de Gracia y Justicia. (24 de julio de 1889). Código Civil. [Real Decreto]. Gaceta de Madrid 206. BOE-A-1889-4763. Disponible en https://www.boe.es/eli/ es/rd/1889/07/24/(1)/con

Reino de España. Ministerio de Justicia. DGSJFP. (5 de octubre de 2010). Régimen registral de la filiación de los nacidos mediante gestación por sustitución. [Instrucción]. BOE 243. BOE-A-2010-15317. Disponible en https://www.boe. es/eli/es/ins/2010/10/05/(1)

Reino de España. SGICSPJ. DGRN. (14 de febrero de 2019a). Actualización del régimen registral de la filiación de los nacidos mediante gestación por sustitución. [Instrucción]. Recuperado de https://www.elindependiente.com/wp-content/uploads/2019/07/instrucci\%C3\%B3n-14-febrero-2019. pdf

Reino de España. SGICSPJ. DGRN. (18 de febrero de 2019b). Actualización del régimen registral de la filiación de los nacidos mediante gestación por sustitución. [Instrucción]. BOE 45. BOE-A-2019-2367. Disponible en https://www. boe.es/eli/es/ins/2019/02/18/(1)

Reino de España. SGICSPJ. DGRN. (18 de febrero de 2009). Autorización de la inscripción de los hijos de una pareja de homosexuales españoles, gestado por una madre de alquiler en california. [JUR2009154581]. Disponible en https:// www.legaltoday.com/historico/jurisprudencia/jurisprudencia-civil/resolucion-de-la-direccion-general-de-los-registros-y-del-notariado-de-18-febrero-2009-2009-04-08/

Reino de España. Tribunal Supremo. Sala de lo Civil. (6 de febrero de 2014). Recurso 245/2012. Resolución 835/2013. [Sentencia STS 247/2014]. Ponente: Rafael Saraza Jimena. Recuperado de https://people.unica.it/sspl/files/2017/12/ STS-06_02_14.pdf 
Reyes, M. J. (2019). El contrato de gestación subrogada en algunos países fuera de la Unión Europea. En, A. Gutiérrez (Coord.), Gestación subrogada: Principales cuestiones civiles, penales, registrales y médicas: su evolución y consideración (1988-2019) (pp. 131-166). Madrid: Dykinson.

Ridao, V. y Ramón, F. (2020). El bebé medicamento en el ámbito de la reproducción asistida en España: cuestiones legales y éticas. Revista Derecho y Salud, 30(1), 39-63. Recuperado de http://www.ajs.es/sites/default/files/2020-05/ vol30n1_02_02_Estudio.pdf

Rodríguez, S. (2019). La protección jurídico-laboral de maternidad ante la "gestación subrogada" y tutela integral de los hijos: antecedentes, estado de la cuestión y perspectivas. Revista de derecho de la seguridad social. Laborum, (18), 53-78. Disponible en https://revista.laborum.es/index.php/revsegsoc/article/view/332

Romeo, A. (2019). Gestación subrogada y movimiento feminista. Una aproximación cuantitativa. Encrucijadas: Revista Crítica de Ciencias Sociales, 18, 1-27. Disponible en https:// recyt.fecyt.es/index.php/encrucijadas/article/view/79209

Rosell, N. y Ramón, F. (2020). Preembriones y fetos sobrantes que no se usan para llevar a cabo las técnicas de reproducción asistida: aspectos éticos y legales. Revista sobre la infancia y la adolescencia, (18), 17-36. https://doi.org/10.4995/ reinad.2020.12669

Ruiz, F. J. (2020). La jurisprudencia del Tribunal Europeo de Derechos Humanos sobre eutanasia y vientres de alquiler. En, A. Sánchez (Coord.), Dignidad y vida humana: eutanasia, gestación subrogada y transhumanismo (pp. 331-360). Cizur Menor: Thomson Reuters Aranzadi.

Salazar, O. (2017). La gestación por sustitución desde una perspectiva jurídica: algunas reflexiones sobre el conflicto entre deseos y derechos. Revista de Derecho Político, (99), 79120. https://doi.org/10.5944/rdp.99.2017.19307 
Sales, L. (2019). La pérdida del interés (superior del menor) cuando se nace por gestación subrogada. Cuadernos de Derecho transnacional, 11(2), 326-347. https://doi.org/10.20318/ cdt.2019.4961

Sánchez, N. (marzo 8, 2020). Louise Brown, la primera bebé probeta: Es triste que la fecundación in vitro siga siendo un tema tabú. elpais.com. Disponible en https://elpais.com/elpais/2020/03/06/mamas_papas/1583486018_035212.html

Sánchez, A. (2019a). El informe de 11 de julio de 2014 de la dirección general de los registros y del notariado. En, A. Gutiérrez (Coord.), Gestación subrogada: Principales cuestiones civiles, penales, registrales y médicas: su evolución y consideración (1988-2019) (pp. 321-346). Madrid: Dykinson.

Sánchez, A. (2019b). Derecho civil y gestación subrogada. En, M. Paz, Mujer, maternidad y Derecho (pp. 749-765). Valencia: Tirant lo Blanch.

Svitnev, K. (2011). Legal control of surrogacy - International perspectives. En, D. Gruyter, Ethical dilemmas in assisted reproductive technologies (pp. 149-164). Jerusalem: Joseph G. Schenker. https://doi.org/10.1515/9783110240214.149

Tomás, D. (2019). La problemática derivada del reconocimiento de los efectos del contrato de gestación subrogada desde la perspectiva del Derecho del trabajo y de la Seguridad Social. Cuadernos de Derecho transnacional, 11(2), 348-359. https://doi.org/10.20318/cdt.2019.4962

Unión Europea. Departamento de Derechos de los Ciudadanos y Asuntos Constitucionales. (2012). Conférence de La Haye de Droit International Privé. [Rapport préliminaire sur les problèmes découlant des conventions de maternité de substitution à caractère International]. Recuperado de https://assets.hcch.net/docs/b4114840-8e21-4f34-b05443fe4c01ab32.pdf 
Valvidares, M. (2020). El marco constitucional del debate feminista sobre la gestación subrogada. En, M. Nuñez (Ed.), Mujer sujeto u objeto de derechos reproductivos: derechos de los menores y maternidad por sustitución (pp. 137-166). Valencia: Tirant lo Blanch.

Vicandi, A. (2019). El futuro de la maternidad subrogada en España entre el fraude de ley versus orden público internacional. En, A. Gutiérrez (Coord.), Gestación subrogada: Principales cuestiones civiles, penales, registrales y médicas: su evolución y consideración (1988-2019) (pp. 303-320). Madrid: Dykinson.

Vidal, J. (2019). Acerca de la regulación jurídica de las técnicas de reproducción humana asistida. Actualidad jurídica iberoamericana, 10(2), 478-513. Recuperado de http://www. revista-aji.com/wp-content/uploads/2019/06/478-513.pdf

Vilar, S. (2019). La inseguridad jurídica derivada de la insuficiente regulación de la gestación subrogada en España. Cuadernos de Derecho transnacional, 11(2), 815-823. https://doi. org/10.20318/cdt.2019.5023

\footnotetext{
* Trabajo realizado en el marco del Proyecto I+D+i «Retos investigación» del Programa estatal de I+D+i orientado a los Retos de la Sociedad del Ministerio de Ciencia, Innovación y Universidades: RTI2018097354-B-100 (2019-2022) y del Proyecto de I+D+i Retos de Investigación, MICINN, del Programa Estatal de I+D+i orientada a los retos de la sociedad (PID2019-108710RB-I00, 2020-2022).
}

Clara Sarasol Barres es graduada en Biotecnología. Línea de investigación en reproducción humana asistida. Universitat Politècnica de València. Escuela Técnica Superior de Ingeniería Agronómica y del Medio Natural (ETSIAMN) (Valencia, España). https://orcid.org/00000001-8634-2973

Francisca Ramón Fernández es Doctora en Derecho de la Universitat de València (España). Profesora titular de Derecho civil. Línea de investigación en reproducción humana asistida Microcluster VCL/CAMPUS “Derecho Sanitario, Genética y Protección Social”. Universitat Politècnica de València. Escuela Técnica Superior de Ingeniería del Diseño (ETSID) (Valencia, España). https://orcid.org/0000-0002-0936-8229. 